\title{
1. Introduction: Crisis? What Crisis? For Whom?
}

\author{
Peter A.G. van Bergeijk, Arjan de Haan and \\ Rolph van der Hoeven
}

The global financial and economic crisis that started in September 2007 with a rather limited problem in a market for non-tradeable goods (houses) challenges the way we have been thinking for decades about globalization, development and vulnerability. The crisis confronts social scientists, not just economists, with many issues that need reflection and therefore this book develops a critical multi-disciplinary perspective and a preliminary assessment of the causes and consequences of the global system breakdown. We will concentrate on the developing and emerging economies in order to gain fresh insights into the challenges that the crisis poses to development strategies and policies, both in the South and the North. The crisis has serious social outfalls, slows down the fight against poverty, sometimes increases poverty, deteriorates income equality and reduces access to social services. The crisis also creates political conflict (amongst others about burden sharing and the external effects of national policies), generates new sets of priorities (in both the developed and the developing world), threatens food security and illuminates the need for better global governance frameworks. From an era in which laissez-faire capitalism seemed to have gained dominance, the role of the state as a leading actor in fostering economic growth and well-being has remained for some and emerged for others as a new paradigm. This is accompanied by the rise of emerging economies, which present alternative development models like that of China.

We have organized the chapters in this book into four parts. Part I deals with concepts of development. One aim of this part is to show how different concepts produced different analyses and policy prescription, but also how crisis per se influences thinking about developmental questions. Part II provides a set of four heterodox (political) economic interpretations that shed a fresh light on the mainstream discourse. Part III provides a global overview 
by means of discussions of regional and country experiences. The final part focuses attention on the next crisis, the timing of which is still uncertain of course, but its eventual occurrence is certain. The remainder of this introductory chapter puts the contributions that build these four parts into perspective.

\section{PERSPECTIVES ON THE CRISIS}

An important theme in this book is that completely different perspectives on the global crisis exist in different parts of the world. Andrew Martin Fischer in Chapter 6 critically analyses the economic perspectives on the causes and culprits of the current crisis as developed in the US and UK (with sources ranging from neo-liberals to New Keynesians) from a post-Keynesian perspective, supported by insights on China. In a nutshell the different perspectives can be related to causality and endogeneity: does saving drive investment (in which case saving glut or underconsumption is the culprit) or does investment drive saving (in which case overconsumption is the culprit). In view of the central position of the saving investment nexus it is astonishing that debt dynamics and the distinction between short-run and long-run effects are often ignored in the policy debate. Analysing these effects in detail, Syed Mansoob Murshed in Chapter 7 shows that Keynesian trade policies that ignore these relations will be counterproductive.

In many countries, particularly and crucially in the poorer countries, crises are regarded as being business as usual. These countries experience and manage slow-downs without perceiving these as the unique events and potential systems breakdown that OECD observers have tended to see. Fantu Cheru (Chapter 4) points out that especially for Sub-Saharan Africa (SSA), the financial crisis was merely the third in a series of crises, as it was preceded by food and fuel crises which impacted them more severely. Also Ben White (Chapter 5) documents the reactions to various economic and social crises since the 1930s. The historical context and earlier crises determine the reactions and perceptions as his case study of Yogyakarta vividly illustrates.

This business-as-usual approach to crisis is one of the important differences between observers in the industrialized countries and in the developing world. Indeed, Jayati Ghosh (Chapter 2) starts with an analysis of earlier crises emphasizing the endemic nature of crisis in the capitalist global order. She shows how the market failed to prevent the social outfall of globalization and the present crisis. It is thus extremely relevant to analyse how countries and institutions in the South have learned lessons from previous crises and how this has influenced their response to the global crisis. 
Importantly, the poorest countries, despite the resilience of their inhabitants, often lack the ability to respond adequately as Duncan Green and Richard King in Chapter 3 demonstrate. This makes the current crisis even more abject as poor countries did not contribute to the crisis in the first place.

\section{MONITORING THE CRISIS}

Many contemporary studies on the impact of the crisis start with the caveat that we do not yet know what has actually happened in many countries - in particular for different parts of the population - simply because adequate real time data (particularly regarding poverty and employment) are not (yet) available. This is especially true for developing and emerging economies. Analysts therefore often have to resort to basic social science detective work, if they want to say something meaningful about the impact and implications of the global crisis for developing countries and emerging markets. Basically four methods can be used in addition to monitoring of key variables:

- the study of previous (financial) crises and their impact on key development indicators,

- the use of (simulation) models,

- indirect observation, and

- field studies that generate qualitative and quantitative observations.

\section{Historical Studies}

Previous cases of financial crises and recessions can be analysed in order to provide a perspective on the potential impact of the global crisis. Well-known examples are: the analysis of the poverty impacts of selected financial crises by Gottschalk (2004), the employment and incomes impacts of financial globalization and financial instability by van der Hoeven and Luebker (2007), the lagged effect of crises on economic growth, employment and debts by Reinhart and Rogoff (2009), the impact of economic downturns on human development indicators by the World Bank (2010d) and the impact of financial crises on net ODA of Japan and the Nordics (Roodman 2008). Karel Jansen (Chapter 17) analyses the Asian crisis of the 1990s for Thailand and Ben White (Chapter 5) analyses Yogyakarta in the 1930s, 1990s and 2000s. 


\section{Simulation Models}

Simulation models can be used to compare scenarios with and without crisis or to analyse differences between pre- and post-crisis periods. Examples are micro-simulation model analyses of poverty and income distribution (Habib et al. 2010 and Sugawara et al. 2010) and the impulse response analysis of external demand shocks and terms of trade losses in World Bank (2010c). Rob Vos (Chapter 18) uses the United Nations Global Policy Model to analyse the risks associated with uncoordinated economic recovery and Syed Mansoob Murshed (Chapter 7) uses a formal mathematical model to analyse short- and long-run effects of protectionist policies.

\section{Indirect Observation}

Indirect observation has been used to get an idea of how economic activity is developing when official statistics do not exist or become available only with considerable delay or are unreliable. Such indirect observations may relate to, for example, declining consumption, school dropouts, increased illnesses, suicide rates as in Chapter 14 by Ashta Kapoor, the impact on the micro finance sector in Latin America (Marconi and Clemens, Chapter 10) or the volume of imports (an indicator that we will use in the next section).

\section{Field Studies}

Quantitative and qualitative field studies provide cases of industries and regions that may shed an early light on the concrete local impact of the crisis on local development. An example is the study by McCulloch and Grover (2010) that combines Indonesia's national household survey with a rapid qualitative study to assess the impact of the crisis on school participation and labour market participation and unemployment in Indonesia. Freek Schiphorst (Chapter 15) traces the crisis in South Africa and the reactions of trade unions.

This book provides a mix of these methods to infer if and how the crisis hits (groups in) the developing and emerging economies. The rich sample of research approaches and methods allow therefore for an informed discussion on the crisis. Crises can impact people in many ways. Sometimes impacts are very clear, but often they are indirect, seemingly absent or less pronounced than expected. Much depends on countries' social policies in place, and the motivations of governments to respond: for example between India and China we witnessed a distinct difference with respect to governments' concerns over rising unemployment, which for the latter was directly informed by the fear of 'social unrest'. 
Given the scale that the financial crisis and the preceding food and fuel crises have had, we think it remarkable how - by comparison - little empirical research has documented the impact of the crisis in countries and places where unemployment statistics are absent and living standards are poorly and infrequently measured. In a sense many contributions in this book attempt to fill this gap: Karin Astrid Siegmann (Chapter 13) reviews jobless growth and economic slumps in Bangladesh, Pakistan and India, Mahmood Messkoub (Chapter 11) deals with the impact of the crisis on employment and poverty in the Middle East and Max Spoor (Chapter 12) describes how unbalanced growth aggravated social fallout in some Eastern European countries.

\section{A CRISIS IN PHASES}

The world economic system is experiencing the largest financial and economic crisis since the 1930s. This crisis so far has followed the classical Minsky pattern ( $c f$. Karel Jansen Chapter 17) and at the global level came in three interlocking waves (Jayati Ghosh Chapter 2 and Rob Vos Chapter 18), leading to important social and governance crises.

\section{Collapse of the Financial Sector}

The first wave was the collapse of the financial sector. Problems in the US subprime mortgage market in 2007 sparked a credit crunch and an immense financial crisis that required massive public interventions. According to UNCTAD (2009a) the developed economies (had to) spend 3.7 per cent of their gross domestic product (GDP) on fiscal stimulus and in addition an astonishing 49 per cent of GDP was made available to support their financial sectors. ${ }^{1}$ On top of this, policy responses included spectacular drops of official interest rates and unprecedented quantitative monetary easing in the US, EU and Japan. The economies outside the OECD on average provided a somewhat stronger fiscal stimulus (about 5 per cent of GDP), but since their financial institutions had not really been infected there was no need to provide public support (the exceptions are India and Saudi Arabia who provided support to the banking sector at the tune of 6 and 20 per cent of GDP, respectively). The policy responses reflected both the global nature of the reduction in effective demand and the OECD-specificity of the shock to the banking and financial sectors. 


\section{Collapse of World Trade and Investment}

At the end of 2008 much attention was drawn to the 20 per cent reduction in the volume of world trade. Many observers pointed to a lack of trade finance as an important driver of the trade collapse (Auboin, 2009). The April 2009 meeting of the G20 took action and announced additional trade financing of $\$ 250$ billion, including instruments to mitigate risks and liquidity support. According to the G20 Trade Finance Expert Group (2009, p. 1) by August 2009, an increase of the G20 members involved in the trade finance initiative from 12 to 16 countries had even increased the potential support available to $\$ 400$ billion. By that time the global trade cycle appeared to be at a turning point, especially for emerging countries in Asia where previous peak levels were being approached and sometimes even passed. The collapse of global investment flows drew somewhat less attention but it was just as spectacular: foreign direct investment (FDI) and cross-border mergers and acquisitions in 2009 declined by 39 and 66 per cent, respectively (UNCTAD 2010a). Again, however, by mid 2009 the foreign investment cycle appeared to be turning around in Asia, in particular in China.

\section{Collapse of Trust in Public Debts}

In April 2010 the third wave became manifest and again the source of the problems was in the OECD, but this time it was not the USA but Europe where the crisis wave started. Like in the USA, in the wake of economic stimulus and in attempts to save large banks from bankruptcy, private debts had been transformed into public debts. Large and unsustainable public debts in Greece threatened to contaminate other European countries in financial distress and trigger a round of debt default. Europe created a stabilization fund of $€ 500$ billion. The IMF co-financed the EU bail-out of Greece and determined the terms of references, supplementing an additional $€ 250$ billion - by far the largest loan arrangement in the history of the IMF. Other European countries such as Spain, Portugal and Ireland were confronted with similar problems. This sovereign risk problem occurred also in the centre and was a consequence of the 2008 crisis (Candelon and Palm 2010). The debt built up in many industrialised countries was the consequence of the stimulus and bail-out response to the crisis. National pressures to reduce the debt by means of fiscal policy may now well frustrate the earlier optimistic attempts for global governance and global stimulus; in effect repeating at an international scale the mistakes of the 1930s. The optimism expressed by the G20 in their 2009 meetings to avoid beggar-thy-neighbour policies through stimulus packages is no longer reflected in the outcome documents of the November 2010 meeting in Seoul. Ghosh (Chapter 2), Cheru (Chapter 4) and 
Vos (Chapter 18) argue that much of the momentum of G20 has been lost and that the G20 can hardly been seen as an institution exercising the minimal international financial brinkmanship.

The experiences during the three crisis waves illustrate both the exceptional nature of the crisis and the insufficiency of (inter)national governance and institutions. It should be noted that policy makers so far did not make the capital mistake which prolonged the crisis of the 1930s: they did not opt for protectionism as in the 1930s (which could very well be countereffective; $c f$. Chapter 7 by Syed Mansoob Murshed). In the same spirit it is noteworthy that the amounts of public financial support and guarantees (and consequently of public debt) have been massive by any standard in the developed and several developing countries.

Table 1.1 Output growth 2008-2009 and IMF projections 2010-2011

\begin{tabular}{lcrrc}
\hline & 2008 & 2009 & 2010 & 2011 \\
\hline World & 2.8 & -0.6 & 4.8 & 4.2 \\
Advanced economies & 0.2 & -3.2 & 2.7 & 2.2 \\
Emerging and developing & 6.0 & 2.5 & 7.1 & 6.4 \\
economies & & & & \\
China & 9.6 & 9.1 & 10.5 & 9.6 \\
India & 6.4 & 5.7 & 9.7 & 8.4 \\
Brazil & 5.1 & -0.2 & 7.5 & 4.1 \\
Russia & 5.2 & -7.9 & 4.0 & 4.3 \\
\hline
\end{tabular}

Source: IMF (2010c), p. 2

However, due to the crisis the global geography of economic strengths and financial fragilities has dramatically shifted. First, all shock waves appear to originate from the centre and not from the periphery as was the case during earlier threats to the global economic system (the Latin American debt crisis in the 1980s, the Russian crisis in the 1990s and the East Asian crisis in the 1990s). Second, the depth of the downturn in the national business cycles prompted some to propose the decoupling hypothesis that assumed that business cycles in the emerging-market economies were not or were less linked to those of the OECD economies. In particular in China and India recovery was relatively quick and the reduction in growth rates was mild (Table 1.1), but nevertheless the social consequences were felt by many families, as Chapter 14 on India by Astha Kapoor and Chapter 16 by Arjan de Haan and Sen Gong in China illustrate. The relatively positive outlook for developing countries and emerging markets may of course be genuine, but it also reflects the fact that their banking system was not exposed to the kind of 
risks that materialized during the first phase of the crisis (so that their downturn could occur later). From this perspective the observation that the world crisis of the 1930 s also started in the centre, but later spread to the periphery may be relevant (Rothermund 1996). Experience of the current crisis is directly informed by recent global changes, particularly the emergence of new key players in the international arena, such as India, China, Mexico and Brazil. More than ever, global flows of capital and trade will determine the wealth; each phase of the crisis demonstrates these interdependencies.

An important aspect of the current crisis is the recognition by the major economies that emerging markets can contribute importantly to its solution. The G8 appears to have dissolved itself into the already existing, but until then rather lacklustre G20. In effect the G20 gave a boost to some form of global governance which several commentators had argued for - well before the outbreak of the crisis (ILO 2004; Stiglitz 2006). However, skirmishes about currencies and a new international financial system as well as calls for fiscal tightening risk (as was manifest in the November 2010 meeting in Seoul) dampens considerably the initial enthusiasm about the role of the G20 as the mechanism for international (financial) governance.

\section{TRANSMISSION MECHANISMS}

It is by now well established that the major transmission mechanisms of the crisis were the reduction in FDI and other capital transfers to developing countries, a decline in trade, a reduction or levelling off in remittance and rethinking of earlier made development aid commitments.

\section{External Finance (FDI, Remittances, Bank Lending and Aid)}

In today's world many channels exist through which economies are linked. International capital flows such as FDI, remittances, bank lending, migration and development aid are influenced by the downturn in OECD economies. International capital flows may provide resources when developing and emerging economies are under strain, but these have 'in spite of soaring needs, not risen - they have fallen' (Addison et al. 2010, p. 1). Three of these flows are especially relevant for developing and emerging economies.

- After six years of uninterrupted growth, FDI flows to developing and transition economies according to UNCTAD (2010a) declined in 2009 by 35 and 39 per cent, respectively. (Chapter 8 by Irene van Staveren provides an overview and analysis of FDI trends and volatility.) 
- In the decade before 2008 remittances showed strong growth and developed into one of the most important capital sources for developing and emerging economies. In 2009 a sharp break in the upward trend occurred although the reductions were limited (see Chapter 3 by Duncan Green and Richard King and Chapter 4 by Fantu Cheru). ${ }^{2}$

- The OECD's Development Co-operation Report 2009 estimated that the underlying trend growth rate of the volume of official development aid (ODA) needed to increase to 11 per cent per year in order to achieve the millennium goals. The results in 2009 were, however, disappointing as the amount of aid increased by 0.7 per cent only. Importantly this is not the result of increased spending but of exchange rate movements that contributed more than 4 percentage points. Actually total ODA in current prices and at current exchange rates decreased from $\$ 122$ billion in 2008 to $\$ 119$ billion in 2009. (Notably, twelve OECD countries reduced ODA.)

\section{Import Contraction and Development Level}

Figure 1.1 analyses the decline in the volume of imports in a cross-country setting for a group of 45 countries over the years 2007-09. ${ }^{3}$ It compares the peak and the trough of the import cycle over this period. The figure first of all illustrates the large variation in country experiences. The Netherlands registers one of the smallest import contractions (of about -11 per cent); the largest contractions of some -45 per cent occur in Belarus and Venezuela.

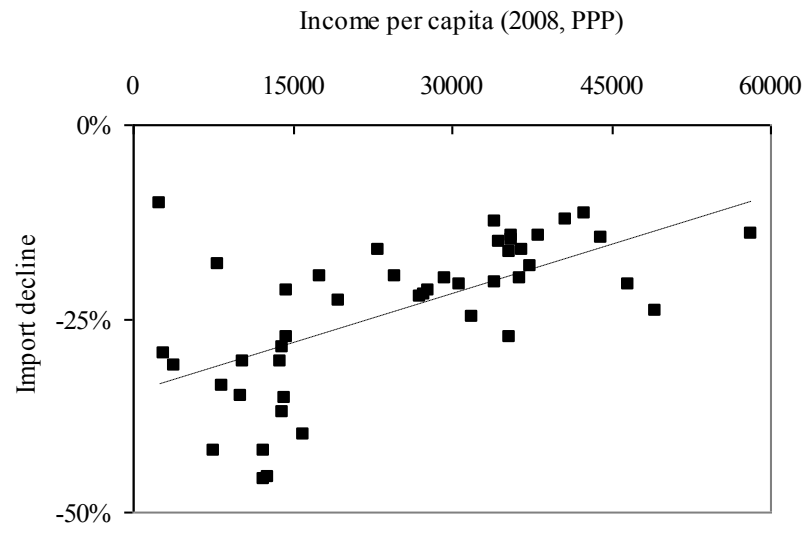

Sources: Calculations based on OECD National Accounts, IMF International Financial Statistics and World Bank indicators data sets

Figure 1.1 Import decline (peak to trough 2007-09) and per capita income 
Importantly, Figure 1.1 relates this decline to the level of development (which is approximated by the income per head in US dollars). The dotted regression line indicates that lower income per head is on average associated with stronger contraction of the volume of imports. The observation that the developing and emerging economies (have to) reduce their import expenditures to a much larger extent suggests that they are hit harder by the crisis than the richer countries. Of course this is not a direct observation, but the finding that many developing and emerging economies are adversely hit by the crisis is corroborated by other recent analyses, including the fieldwork studies in this volume.

\section{WHERE DOES THE CRISIS BITE?}

The key World Bank (2010c) scenarios for 2005-20 still foresee a reduction in the percentage of the world population living at an income level of less than $\$ 1.25$ a day, but the crisis would add between 53 and 214 million people in absolute poverty in comparison to the pre-crisis trend. Of course, these effects are different in each country and locality. According to a simulation exercise (Habib et al. 2010), in Bangladesh and the Philippines where growth slowed down, poverty is expected to be respectively 1.2 and 1.5 percentage points higher (or 1.4 and 2 million more poor people) than would have been the case without the crisis. In Mexico, where GDP contracted by nearly 7 per cent in 2009 , the poverty rate may rise by nearly 4 percentage points in two years. The structure of the economy and the income distribution determine where the income declines hit most. Habib et al. (2010) show that expected income declines are largest in the middle income groups particularly in Bangladesh and the Philippines, whereas they are very significant for the lowest income group in Mexico. Their model suggests that the macroeconomic effects trickle down to the (new) poor and especially a middle income group of 'crisis vulnerable' (typically working in exportoriented industries and located in urban areas) with substantial poverty and distributional effects and potentially important effects on long-term growth (see also Khanna et al. 2010). These effects are often mirrored geographically, with areas dependent on export industries and particular sectors being affected directly, such as Guangdong in China (with a lagged impact on the rural areas from where migrants come) or Sirat in India (see Chapter 14 by Astha Kapoor). 


\section{Human development}

A reduction in economic growth in the past has been associated with worse performance on human development goals such as health, education and gender. The World Bank (2010c) has analysed the experiences in 163 countries over the period 1980-2008 finding that contractions of economic activity have been associated with deteriorating social indicators.

Moreover, the impact of growth and decline on human development is not symmetrical (Figure 1.2) as the deterioration during a growth deceleration is stronger than the improvement during an upswing. Life expectancy at birth on average declines by 10 per cent as infant and child mortality increase by 50 to 75 per cent, respectively. Cuts in social expenditure may not only deteriorate performance regarding education and health directly but may in addition exert a negative influence over very long periods.

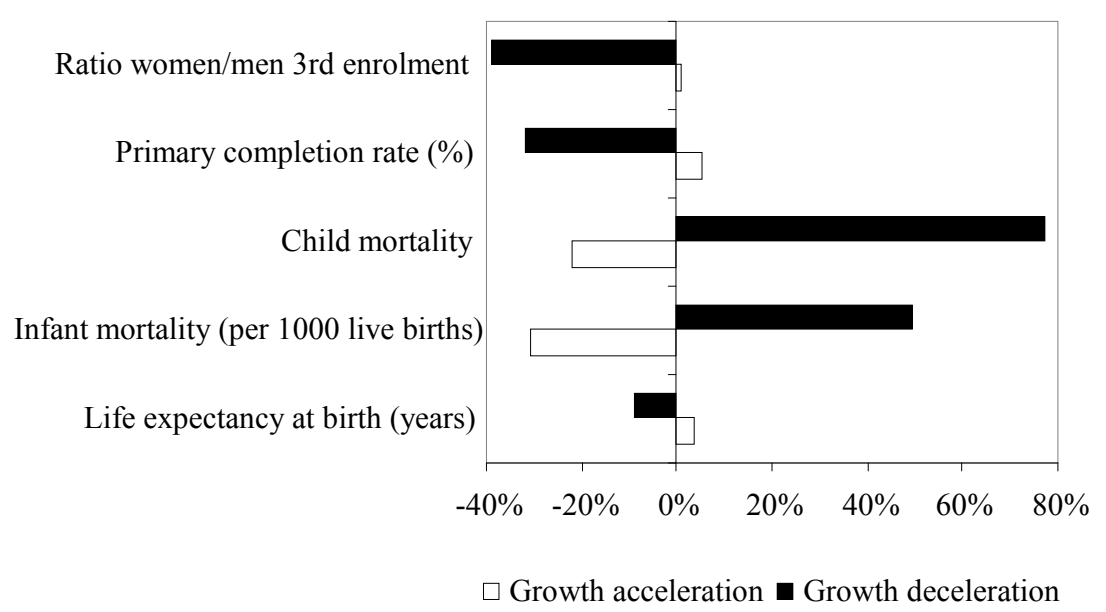

Source: Calculated from World Bank (2010c), Annex 2.1

Figure 1.2 Impact of growth accelerations and decelerations on selected human development indicators

\section{Gender and Child Wellbeing}

Duncan Green and Richard King (Chapter 3) report that many women are paying a particular price through their additional unpaid work to support their households, through migration, through additional work in the informal sector and by eating less. Karin Astrid Siegmann (Chapter 13) argues that only a few analyses have highlighted the gender impact of the crisis, not only 
in terms of statistics but also in terms of changing norms. In some cases the crisis reinforced existing gender norms, but the crisis has also called in question certain norms. A detailed assessment of economic and sociological phenomena is called for.

UNICEF has documented the impact of the global economic crisis on children in Ghana, Burkina Faso and Cameroon (Cockburn et al. 2010). In Ghana, child wellbeing was affected by a sharp increase in monetary poverty and hunger, while in Burkina Faso school participation dropped and child labour force participation increased (see also the next section). Friedman and Schady (2009), using household level data, show that infants die more often during crises because families tend to spend less on health and nutrition. Their estimate suggests that SSA has experienced 30,000 to 50,000 extra child deaths in 2009, and that girls are more likely to die compared to boys. World Bank research in Uganda and Madagascar shows that when household income declines, girls are first to be pulled out of schools.

In East Asia also impacts can be severe. According to Bhutta et al. (2009) the mortality rate among children younger than 5 years in severely affected countries could increase by 3 to 15 per cent, lower birth weight could increase by 5 to 10 per cent, and rates of childhood stunting could increase by 3 to 7 per cent. (Local impacts are also documented in Chapter 4 by Duncan Green and Richard King, Chapter 5 by Ben White and Chapter 14 by Astha Kapoor.)

\section{Incomes, Employment and Inequality}

It is still too early to make definite statements on the impact of the crisis on incomes, employment and inequality but nevertheless some worrying facts and trends can be observed. One should not fall into the simplistic trap of looking only at those who have been negatively affected by the crisis. This is so, because the current crisis cannot be seen as an isolated event. The crisis is related to processes of liberalization and globalization which ran out of control. Globalization itself resulted in a greater schism between those who profited and those who were excluded. It is simply wrong to argue that those who were or are excluded from globalization, and thus did not profit in the run up to crisis, can now not lose from the crisis. Indeed the situation of the socially excluded may very well deteriorate at times when governments are reducing social expenditure to reduce public debt built up to save the jobs of the bankers that created the crisis.

Table 1.1, based on information from the various chapters, traces the positions of various socioeconomic groups in various countries' groupings at several stages of the crisis. With the hindsight of the crisis we get a rather pessimistic picture to the extent that in developed countries poorer parts of 
the population lagged behind in profiting from the globalization bubble before the crisis. For example salaries of lower skilled workers in the USA have not increased over the last 25 years and those of German workers increased only slightly over the last 10 years. The top 1 per cent of households in the USA accounted for only 8.9 per cent of total income in 1976 compared to 23.5 per cent in 2007 (Rajan 2010).

Table 1.1 Effects on various socioeconomic groups in different countries

\begin{tabular}{|c|c|c|c|c|c|}
\hline & $\begin{array}{l}\text { Pre } \\
\text { crisis }\end{array}$ & Crisis & $\begin{array}{r}\text { Postcrisis } \\
\text { stimulus } \\
\end{array}$ & $\begin{array}{l}\text { Postcrisis } \\
\text { fiscal austerity }\end{array}$ & $\begin{array}{c}\begin{array}{c}\text { Back on } \\
\mathrm{y} \text { track }\end{array} \\
\end{array}$ \\
\hline \multicolumn{6}{|c|}{ Developed countries } \\
\hline Capital owners & ++ & - & ++ & + & $?$ \\
\hline Skilled workers & ++ & - & + & - & $?$ \\
\hline Unskilled workers & - & - & + & - & $?$ \\
\hline Excluded & - & 0 & 0 & - & $?$ \\
\hline \multicolumn{6}{|c|}{ Emerging developing countries } \\
\hline Capital owners & ++ & + & ++ & + & $?$ \\
\hline Skilled workers & ++ & - & + & + & $?$ \\
\hline Unskilled workers & + & - & + & - & $?$ \\
\hline Peasants & - & - & + & - & $?$ \\
\hline \multicolumn{6}{|c|}{ Poor developing countries } \\
\hline Capital owners & + & 0 & + & + & $?$ \\
\hline Skilled workers & + & - & + & - & $?$ \\
\hline Unskilled workers & - & - & + & - & $?$ \\
\hline Peasants & - & 0 & + & - & $?$ \\
\hline
\end{tabular}

It appears therefore that the poorer segments in the developed countries face a triple whammy: they did not profit from globalization, they were hardest hit in terms of unemployment and are now bearing the consequences of fiscal tightening following the massive stimulus and bank bail-outs.

The situation for developing countries is even more complex. The growth path of the emerging economies shows similar movements as those of developed countries but of less intensity and thus they were less affected by the crisis. However, except for some Latin American countries, the growing inequality which was building up or being reinforced is not yet being halted, and wage shares in most emerging market economies are still declining, which has a negative effect on domestic demand. The poorer developing countries, mainly in Africa, were less affected as their banking system was less developed, but suffered from slower exports proceeds, remittances and the threat of lower aid in the development of the crisis. 


\section{WHAT TO DO?}

Bold measures have been taken to prevent a worsening of the crisis. The first reaction to the crisis was a consensus on stimulus packages and an attempt to improve global governance by resurrecting the dormant G20 structure. Here the reaction both in developed and developing countries was different than during the 1930s. However, both domestically and internationally, these initiatives have not been followed by deeper and more structural policy changes, which are definitively needed. The November 2010 meeting of the G20 did not provide the necessary breakthrough in terms of improving global governance, as discussed by Ghosh, Green and King, Cheru and Vos in their respective chapters in this volume. Renewed efforts to improve global governance are called for.

At the international level - despite some changes in the Basle guidelines banks can still dictate markets and bonuses. The support given to banks in most western countries has quickly led to easy profits and a business-as-usual attitude by the banks. Also the absence of an integrated financial system, the continuing global imbalances and the continuing embracement of the export growth model may lead to currency wars. Fiscal policy is another area where national and international concerns intersect. After an unprecedented fiscal expansion to boost growth in all crisis-affected countries, fiscal retrenchment is now advocated by many politicians. A disorderly retrenchment, however, would make it more difficult for the world economy to grow, thus frustrating lowering debt to GDP ratios and jeopardizing job creation (Karin Astrid Siegman Chapter 13 and Mahmood Messkoub Chapter 11).

Another challenge to this crisis is policy change at the national and local level. A first requirement is to bring down the absurdly high levels of income inequality (van der Hoeven 2010). This is not only necessary for having social pacts to fend off the social effects of further crises but also to achieve a more balanced wage-led growth path with less reliance on foreign demand as Jayati Ghosh (Chapter 2) and Max Spoor (Chapter 12) argue. More attention needs to be given to employment creation. Governments have been acting during the crisis as bankers of last resort but not as employers of last resort (see Chapter 9 by Rolph van der Hoeven). Special policies to stimulate employment are necessary, since even a return to economic growth after the crisis does not lead automatically to sufficient growth in jobs. Hysteresis and ratchet effects are a reality of this crisis as they were of earlier crises (Reinhart and Reinhart, 2010).

Furthermore, increasing poverty and its very different manifestations across groups and localities make design of national policy responses a crucial topic. Policies need to be in place - preferably before a crisis hit - not only for the structurally deprived and the chronic poor, and the diversity 
within this group, but also for those directly affected by the crisis, or the manifold crises, particularly in SSA. While much attention has been paid recently to cash transfers, particularly those of Latin America, and how these were extended during the crisis (as in the case of Brazil's Bolsa Familia), the crisis has also led to renewed questions whether a strengthening of traditional social security systems and social programmes can deal with the new vulnerable, or whether systems should be expanded to take these groups into account. It has often been posited that the financial crisis provides an opportunity for the formulation of new social protection policies (Prasad and Gerecke 2010), but there is also evidence of reluctance to invest in social protection policies which are often regarded as 'unproductive' spending.

Responses to crises need to take account of the possible impact on services and human development indicators. According to Ortiz et al. (2010), the importance of social spending appears generally to be better understood during this crisis than during earlier crises. Still average growth in social spending in developing countries has slowed down to 2 per cent during 2008-09, barely exceeding population growth. As these increases were largely facilitated by an overall expansionary fiscal stance, current policies of fiscal retrenchment may well result in lower social spending.

Not all measures can be implemented centrally. The participation of those affected is needed if policy measures become grounded in political reality. Freek Schiphorst (Chapter 15) shows how difficult that is in South Africa. Fantu Cheru (Chapter 4) even calls for alternative formulations of democracy. How international solidarity can play a bigger role is truly a challenge that requires political leadership both in the North and the South.

In addition to political change at a global and national level, the development co-operation community needs to change its perspective on and its thinking about development and about development aid. Lessons related to aid effectiveness at the micro-level may not offer guidance when economies are threatened with collapse and societies may thus be in danger of disintegrating. According to Green and King (Chapter 3), the host South Korea at the November 2010 G20 meeting in Seoul was keen to establish development as a core mission of the group, and even secured an agreement for a 'Seoul Development Consensus for Shared Growth', based on nine 'pillars': infrastructure, private investment and job creation, human resource development, trade, financial inclusion, growth with resilience, food security, domestic resource mobilization and knowledge sharing. However, this call for a rethinking of development aid was overshadowed by the disagreements on reforming the international financial governance system. Giving this, it is unlikely that Western aid donors will have a strong incentive to change quickly and drastically their existing patterns of patronising (people in) developing countries. This is a missed opportunity, also because solutions for 
a next crisis have to be found in the development of the South, its role in global governance and a greater understanding and recognition of the South's potential and the ability to develop that, by the North.

\section{NOTES}

1 The stimulus was to be spent over a number of years. On an annual basis it is less than the fall out in aggregate demand. These numbers do not account for the countercyclical effect of automatic stabilizers.

2 Remittances continued to increase in South Asia and, on average, for lowincome countries during 2009.

We use the method of indirect observation and analyse the relationship between the level of growth and the contraction of imports (trade, unlike more comprehensive and complex phenomena such as income, is observed reasonably accurately and published without much delay and the impact of a financial crisis should be expected to be most visible and unambiguous in the development of the volume of imports; see Van Bergeijk 2009a). We find strong indications that import contractions are larger in countries with lower per capita income and arguably this implies a stronger impact on economic activity in these countries. 